\title{
Evidence of Co and Triple Infections of Hepatitis B and C Amongst HIV Infected Pregnant Women in Buea, Cameroon
}

\author{
George Mondinde Ikomey ${ }^{1,}$, , Graeme Brendon Jacobs ${ }^{3}$, Becky Tanjong ${ }^{2}$, Martha Tongo Mesembe ${ }^{1}$, \\ Agnes Eyoh $^{1}$, Emilia Lyonga ${ }^{1}$, Ebot Mfoataw ${ }^{2}$, Rose Ngoh $^{1}$, Cynthia Raissa Tamandjou ${ }^{3}$, \\ Greg Ikomey $^{1}$, Marie Claire Okomo Assoumou ${ }^{1}$ \\ ${ }^{1}$ Center for the Study and Control of Communicable Diseases (CSCCD), Department of Microbiology, Haematology, Parasitology and \\ Infectious Diseases of Medicine, University of Yaoundé, Yaounde, Cameroon \\ ${ }^{2}$ Faculty of Health Sciences, University of Buea, Buea, Cameroon \\ ${ }^{3}$ Division of Medical Virology, Faculty of Medicine and Health Sciences, Stellenbosch University, Tygerberg, South Africa
}

\section{Email address:}

Mondinde@yahoo.com (G. M. Ikomey), graeme@sun.ac.za (G. B. Jacobs), becktanjond@yahoo.com (B. Tanjong), mtmesembe@yahoo.com (M. T. Mesembe), e_eyoh@yahoo.com (A. Eyoh), emilialyo@yahoo.co.uk (E. Lyonga), ebotmfoataw@yahoo.com (E. Mfoataw),craissat@gmail.com (C. R. Tamandjou),rosengoh@yahoo.com (R. Ngoh), gregory.ikomey@cnps.com (G. Ikomey), mcokomoas@yahoo.fr (M. C. O. Assoumou)

${ }^{*}$ Corresponding author

\section{To cite this article:}

George Mondinde Ikomey, Graeme Brendon Jacobs, Becky Tanjong, Martha Tongo Mesembe, Agnes Eyoh, Emilia Lyonga, Ebot Mfoataw, Rose Ngoh, Cynthia Raissa Tamandjou, Greg Ikomey, Marie Claire Okomo Assoumou. Evidence of Co and Triple Infections of Hepatitis B and C Amongst HIV Infected Pregnant Women in Buea, Cameroon. Science Journal of Public Health. Vol. 4, No. 2, 2016 , pp. $127-131$. doi: $10.11648 /$ j.sjph.20160402.17

Received: January 17, 2016; Accepted: February 1, 2016; Published: March 28, 2016

\begin{abstract}
Little epidermiological data is available on the prevalence of HIV, Hepatitis B and C, Co-and or triple infection during pregnancy in Cameroon as well as many other resource limited settings. HIV and Hepatitis B and C are major public health concerns world wide. Our study aimed at assessing the seroprevalence of Hepatitis B and C amongst HIV infected pregnant women in Buea, located in the Southwest region of Cameroon. A Cross-sectional study on consented pregnant women were conducted from March 2015 to August 2015. HIV-1 infections were detected using the national HIV-1 test algorithms. Hepatitis B surface antigen (HBsAg), anti-HBe and anti- Hepatitis C (anti-HCV) were detected using Enzyme linked Immunosorbent Assays (ELISAs). Of the 1230 recruited pregnant women, 97/1230 (7.8\%) (95\% CI: 3.5, 29.0\%) were confirmed HIV-1 positive. HIV/HBV co-infection were observed in 14/97 (14.4\%) (95\% CI: 39.8, 100\%), whilst $11 / 97$ (11.3\%; 95\% CI: 27.5, 100\%) were HIV/HCV co-infections. Two HIV-infected pregnant women (8/97(8.2\%; 95\% CI: 0.1, $17.2 \%)$ ) were $\mathrm{HIV} / \mathrm{HBV} / \mathrm{HCV}$ triple-infected. Anti-HBc was detected in all HBV-infected pregnant women $(14 / 14 ;(100.0 \%))$ (95.0\% CI: 39.8, 100.0\%). Seropositivity for HIV-1 was higher (37\%) amongst subjects aged between 32-37 years, whilst none was found above 40. From our results we conclude that Co- and triple infections of HIV, Hepatitis B and C were present amongst pregnant women in Buea. Epidemiological data generated from this study are limited due to the existence of triple infected. It will therefore serve as a guide to the government policies to reinforce screening, treatment and prevention strategies, through its Mother-to-Child-transmission (pMTCT) Programme nationwide.
\end{abstract}

Keywords: Hepatitis B and C, Cameroon, Co-infection

\section{Introduction}

According to the World Health Organization (WHO), HIV-1 accounts for approximately 35.6 million global infections [2]. Hepatitis B virus (HBV) and Hepatitis C virus (HCV) account for around 240 million and 170 million chronic infections, respectively. $\mathrm{HBV}$ and $\mathrm{HCV}$ are the most common causes of viral hepatitis infections in Cameroon [1-2]. Acute viral infection is characterized by nausea, malaise, abdominal pain and jaundice. In most cases the infection is asymptomatic, 
while the persistence of viremia after a period of six months leads to chronic hepatitis. The latter remains silent and is the main risk factor for end-stage liver diseases [4].

In the HIV-infected population, $\mathrm{HBV}$ and $\mathrm{HCV}$ coinfection numbers vary from 2-4 and 3-4 million, respectively [3-5]. It is estimated that one-third of deaths recorded in HIV-infected patients are associated with severe liver fibrosis/cirrhosis or hepatotoxicity associated with antiretroviral therapy (ART). Little is known about HIV, HBV and HCV triple infections. The rate of co-infections and triple infections in HIV, HBV and HCV patients varies worldwide and depends on the different geographic regions, risk groups and exposure involved [7-11]. The presence of co- and or triple infections of these viruses are of major public health concern, owed to their high morbidity and mortality rate [12-13].

Although the routine screening of $\mathrm{HBV}$ in pregnant women has been recommended by the WHO, implementation remains limited due to the high costs associated and required infrastructure needed in resource-limited settings, such as Cameroon.

National studies performed in different settings have recorded high prevalence rates of $\mathrm{HIV}, \mathrm{HBV}$ and $\mathrm{HCV}$ mono-infections, ranging from $4.0 \%$ to $6.9 \%, 8.0 \%$ to $12.0 \%$ and $3.9 \%$ to $13.0 \%$, respectively [14 17]. General global prevalence of $\mathrm{HIV} / \mathrm{HBV}$ co-infection rates ranges from $10.0 \%$ to $12.0 \%$, whilst $\mathrm{HIV} / \mathrm{HCV}$ co-infection has recorded $3.0 \%$ to $5.0 \%$ prevalence rates $[17-18]$. The rate of $\mathrm{HIV} / \mathrm{HBV}$ and $\mathrm{HIV} / \mathrm{HCV}$ co-infection remains a concern in the Cameroonian antenatal population. Data on triple infection is scarce. This study aimed at assessing the seroprevalence of HIV, HBV and HCV amongst pregnant women. This study re-inforces the need for compulsory background screening and assisting the implementation of $\mathrm{HBV}$ prevention of Mother-to-Child transmission [PMTCT] programs.

\subsection{Study Design}

This was a cross-sectional descriptive study of a cohort of pregnant women visiting the various Antenatal Clinics (ANC) in Buea from March 2014 to August 2014. A total of 409 participants were enrolled.

\subsection{Study Setting}

Buea, capital of the southwest region of Cameroon, is a semi urban city inhabited by about 200000 multicultural individuals. The city was reported to have the highest prevalence of HIV infection among pregnant women attending ANC, which varied between $7.8 \%-8.0 \%$ in the years 2000, 2002 and 2011 [8].

\section{Method}

In this study, 1230 consenting women were enrolled. Socio-demographic and explanatory variables were collected using a structured questionnaire. Venous blood was collected from each participant into Serum separation tubes (SST).
Serum samples were stored at $-20^{\circ} \mathrm{C}$ until use. The samples were transported and analyzed to the Center for the Study and Control of communicable Diseases of the Faculty of Medicine and Biomedical Sciences of the University of Yaoundé 1 (CSCCD/FMBS). HIV testing was performed following the national HIV testing algorithms, which includes 2 rapid test kits (Abbott Determine, France) and (SDBioline HIV1 / 2, Germany), followed with a confirmation test using a $3^{\text {rd }}$ generation Enzyme linked Immunosorbent Assay (ELISA) (Murex version 1.3, France). $\mathrm{HBV}$ and HCV serological markers were detected using a rapid detection kit (Acon, France) (for $\mathrm{HBsAg}$ and $\mathrm{HCV}$ antibodies) and confirmed with a $3^{\text {rd }}$ generation Ultra Monolisa ELISA kit for HBsAg, anti-HBe and anti-HCV (Bio-Rad laboratories, France).

Statistical analysis

Statistical analysis was performed using SPSS version 14.0. The Pearson chi-square analysis was used for the distribution of HIV-1 infection among the various age groups. Descriptive statistics and binary logistic regression of Fischer's exact were used. We considered a 95\% confidence interval, $5 \%$ margin of error, $50 \%$ proportion and $5 \%$ contingency to justify our sample size.

\section{Results}

\subsection{Socio-Demographic Characteristics}

A total of 1230 pregnant women were included in the study. The mean age of the study participants was 25.72 (SD. \pm 5.14$)$ years old. Table 1 shows detailed sociodemographics of study participants.

Table 1. Socio-demographic characteristics.

\begin{tabular}{ll}
\hline Characteristics & Study population, $\mathbf{n} / \mathbf{N}(\%)$ \\
\hline HIV Status & \\
Positive & $97 / 1230(7.8 \%)$ \\
Negative & $1000 / 1230(81.2 \%)$ \\
Marital Status & \\
Single & $700 / 1230(56 \%)$ \\
Married & $530 / 1230(44 \%)$ \\
Educational levels & \\
Formal & $900 / 1230(73 \%)$ \\
Non formal & $330 / 1230(27 \%)$ \\
\hline
\end{tabular}

Table 2. Age distribution and prevalence of $H B V, H C V$ Co-Infection among $H I V-1$ infected pregnant women.

\begin{tabular}{ll}
\hline Characteristic & HIV-1 infected pregnant women, n/N (\%) \\
\hline Mean age: 25(SD. \pm 5.14$)$ & \\
$20-25$ & $16 / 79(20 \%)$ \\
$26-31$ & $18 / 97(18 \%)$ \\
$32-37$ & $24 / 97(30 \%)$ \\
$38-43$ & $19 / 97(24 \%)$ \\
$>40$ & Noon $/ 97(0 \%)$ \\
Co-infection & \\
HIV/HBV & $14 / 97(17.8 \%)$ \\
HIV/HCV & $11 / 97(11.2 \%)$ \\
Triple-infection & \\
HIV/HBV/HCV & $8 / 97(8.2 \%)$ \\
\hline
\end{tabular}




\subsection{Prevalence of HIV, HBV and HCV Co - infection}

Of the 1230 recruited pregnant women, 97/1230 (7.8\%) (95\%CI: 3.5, 29.0\%) were confirmed HIV-1 positive. HIV/HBV co-infection were observed in 14/97 (14.4\%) (95\%CI: 39.8, 100\%), whilst 11/97 (11.3\%; 95\%CI: 27.5 , $100 \%$ were HIV/HCV co-infections. Two HIV-infected pregnant women $(8 / 97(8.2 \%$; 95\%CI: $0.1,17.2 \%)$ were $\mathrm{HIV} / \mathrm{HBV} / \mathrm{HCV}$ triple-infected. Anti-HBc was detected in all HBV-infected pregnant women $(14 / 14 ;(100.0 \%)(95.0 \% \mathrm{CI}$ : $39.8,100.0 \%)$. Seropositivity for HIV-1 was higher $(37 \%)$ amongst subjects aged between 32-37 years, whilst none was found above 40. Prevalence of co- and triple infections (with $\mathrm{HIV}, \mathrm{HBV}$ and $\mathrm{HCV}$ ) did not vary with age.

\section{Discussion}

The purpose of this study was to record and step-up epidemiological data on co-and/or triple infection of HIV, HBV and HCV amongst HIV-1 infected pregnant women attending antenatal clinics in the south west regional capital of Buea, Cameroon.

The mean age of the study participants was 25.72 [SD. \pm 5.14 ]. In this study, $7.8 \%$ of the pregnant women were seropositive for HIV-1 and none for HIV-2. This suggests that HIV-1 is prevalent in this region, which concords with its predominance worldwide [1-3]. The HIV seropositivity was higher [23.2\%] among the subjects aged between 25 and 40 years, whilst none was found above 40 years. The high HIV-1 prevalence in this group could be attributed to the fact that women at this age are more likely exposed due to high sexual activities and unprotected sex in an effort to fall pregnant and have children.

The overall results of this study indicate a high prevalence of HIV co-and triple infections of Hepatitis B and C among pregnant women $[12.5 \%, 9.6 \%$ and $6.6 \%$ in Buea. However, other studies reporting on the prevalence of HBsAg among HIV-infected patients have described a HBsAg prevalence rate varying from $5.4 \%$ to $6.0 \%$ among pregnant women in rural settings and from $7.0 \%$ to $12.5 \%$ in urban settings [4-7]. The high HBsAg rate in urban settings could be a result of improved laboratory facilities, increased awareness and perhaps success in the implementation of systematic HBV screening of pregnant women in PMTCT program whose implementation in the rural areas is below $2 \%$ [7-9].

The high prevalence of HBsAg observed in this study among pregnant women could be an indication that pregnant women serve as a very important reservoir to fuel the HBV epidemic in the Cameroonian general population. However, previous studies indicate that in areas of high HBV prevalence (i.e. $\geq 8 \%$ ) like Cameroon, horizontal transmission during childhood is predominant [10-12]. Heterogeneity in religion, culture and practices, and a high HIV burden are factors that might influence the HBV and HCV epidemiology in sub-Saharan Africa (SSA). From our results, the prevalence of $\mathrm{HIV} / \mathrm{HBV}$ and $\mathrm{HIV} / \mathrm{HCV}$ coinfections were $12.5 \%$ and $9.3 \%$ respectively.
HIV-1 has been shown to promote HBV and HCV viral replication and viral reactivation leading to an increased progression towards fibrosis and liver cirrhosis [13-15]. These results, though high, are similar to those reported by Flambo et al [2014] [13-16] and Fomulu et al [2013] [16-18]. However, our results are somehow contradictory to Gutierrez, et al [2012] [12-18]. This contrast could be due to the fact that no pregnant women were triple infected. Moreover, the clearly defined wide geographical variation of HIV-1 seroprevalence also defines the varying co and triple infections rate amongst pregnant women within Cameroon. The variations may be a reflection of the differences in sexual practices and behavior, awareness of HIV infection and testing, sociocultural practices and accessibility to healthcare.

From this study, the prevalence of HIV/HBV co-infections among HIV-infected pregnant women in Buea is $12.5 \%$. This reported prevalence is higher than reports from other studies carried out within SSA countries, like the $4.9 \%$ reported by Baye [2014] [12] among HIV-infected patients in Dessie Referral Hospital, Ethiopia. Opaleye et al., [2010] [13-15] reported a prevalence rate of 5.4\% among blood donors in Benin City, Nigeria. The differences and low prevalence rates recorded in these studies could be attributed to the difference in patient selection. The HIV/HBV co-infection rate is high $[12.5 \%]$ in this study, and is comparable to what is found by other investigators in neighboring countries like Nigeria (Obi et al., 2007 [20]; Callebeng et al., 2006 [14] TremeauBravard et al., 2012 [17-20]. In a study by Tremeau-Bravard et al., [2012] a 7.9\% HIV/HBV co-infection rate was reported. HBV prevalence among pregnant women varies from one country to another, and mostly ranges between $6 \%$ and $9.5 \%$ [22-24]. These results will be used to establish appropriate management and preventive policies for women attending antenatal clinics in Cameroon.

From the above discussion, we therefore propose that, the Government and Ministry of Public Health should rely on surveillance data to track the incidence of acute infection amongst the three viruses. Development and evaluation of programs and policies designed to prevent infection and minimize the public health impact of viral hepatitis, in HIV infected population.

Effective systems for conducting surveillance for chronic $\mathrm{HBV}$ and HCV infections are needed to ensure accurate reporting of all cases and to support and evaluate prevention activities. The Ministry Public Health should strengthen guidelines for the Universal screening of all pregnant women in both the rural and urban regions in the country through the PMTCT programme for hepatitis nationwide.

\section{Limitations}

Our results had as main bias that pregnant HIV-infected women with acute or chronic viral hepatitis represent only those relatively few infected persons who were detected, and diagnosed. It should also be noted that, most HIV-infected pregnant women with viral hepatitis infections are not 
reported, resulting in under estimates and variable data quality. Moreover, viral characterization was not performed owed to the unavailability of infrastructures. Also, although HBV serological assays reported on the presence of active HBV infection, confirmation with nucleic acid testing (NAT) would have been useful to demarcate active infection from occult infection. The strengthen of this study is the fact that it is the first to demonstrate the presence of triple infections of $\mathrm{HIV}, \mathrm{HBV}$ and HCV amongst pregnant women in Cameroon.

\section{Conclusion}

This study described the presence of HIV/HBV, HIV/HCV co-infections and triple co-infections amongst pregnant women in Buea, Cameroon. More epidemiological data are needed to guide future government policies aimed at reinforcing screening, treatment and prevention strategies in the antenatal population.

\section{Authors' Contributions}

GMI conceived and designed the study, implemented sample collection and laboratory analysis, and wrote the first draft of manuscript. MCOA MM contributed in design and supervised laboratory analysis. BT participated in Laboratory analysis. GJ AE, EL EM, MI, CT and RN all revised the draft of manuscript. All authors read and approved the final manuscript.

\section{Acknowledgements}

The CSCCD laboratory, where this study was conducted, was supported by the Faculty of Medicine and Biomedical Sciences of the University of Yaoundé 1, Cameroon.

\section{References}

[1] WHO: Hepatitis B. Fact Sheet No. 204. Geneva, Switzerland: World Health Organization; 2014. Teo E-K, Lok ASF: Epidemiology, transmission, and prevention of hepatitis B virus infection. In UpToDate. Edited by Basow DS. Waltham, MA: UpToDate; 2009. WHO: Hepatitis B vaccines.

[2] F, Keugoung B, Fouedjio JH, Kouam N, Mendibi S, DongtsaMabou J: High Rates of Hepatitis B and C and HIV Infections among Blood Donors in Cameroon: A Proposed Blood Screening Algorithm for Blood Donors in ResourceLimited Settings. J Blood Transfus 2012, 2012: 1-7.

[3] Noubiap JJN, Joko WYA, Nansseu JRN, Tene UG, Siaka C: Sero-epidemiology of human immunodeficiency virus, hepatitis B and C viruses, and syphilis infections among firsttime blood donors in Edéa, Cameroon. Int J Infect Dis 2013, 17:e832-e837. PubMed Abstract | Publisher Full Text.

[4] Euler GL, Wooten KG, Baughman AL, Williams WW: Hepatitis B surface antigen prevalence among pregnant women in urban areas: implications for testing, reporting, and preventing perinatal transmission. Pediatrics 2003, 11: 11921197.
[5] Gutierrez, R. Garcia, E. Ntsama, C. Parra-Fariñas, M. C. Fariñas and C. Fariñas-Alvarez HBV, HIV seroprevalence high among pregnant women at Cameroon clinic.

[6] Chiaramonte M, Stroffolini T, Ngatchu T, Rapicetta M, Lantum D, Kaptue L, Chionne P, Conti S, Sarrecchia B, Naccarato R: Hepatitis B virus infection in Cameroon: a seroepidemiological survey in city school children. $J$ Med Virol 1991, 33: 95-99.

[7] Njouom R, Pasquier C, Ayouba A, Tejiokem MC, Vessiere A, Mfoupouendoun J, Tene G, Eteki N, Lobe MM, Izopet J: Low risk of mother-to-child transmission of hepatitis $\mathrm{C}$ virus in Yaounde, Cameroon: the ANRS 1262 study. Am J Trop Med Hyg 2005, 73: 460-466. PubMed Abstract | Publisher Full Text.

[8] Fomulu NJ, Morfaw FL, Torimiro JN, Nana P, Koh MV, William T: Prevalence, correlates and pattern of Hepatitis B among antenatal clinic attenders in Yaounde-Cameroon: is perinatal transmission of HBV neglected in Cameroon? BMC Pregnancy Childbirth 2013, 13: 1-10. PubMed Abstract BioMed Central Full Text | PubMed Central Full Text.

[9] Frambo AA, Atashili J, Fon PN, Ndumbe PM: Prevalence of HBsAg and knowledge about hepatitis B in pregnancy in the Buea Health District, Cameroon: a cross-sectional study. BMC 2014 Jun 25; 7: 394. doi: 10.1186/1756-0500-7-394.

[10] Parry E, Godfrey R, Mabey D, Gill G: Hepatitis Viruses. In Princ Med Afr. 3rd edition. Cambridge: Cambridge University Press; 2009: 710-712.

[11] Collenberg, T. Ouedraogo, J. Ganame, H. Fickenscher, G. Kynast-Wolf, H. Becher, et al. Seroprevalence of six different viruses among pregnant women and blood donors in rural and urban Burkina Faso: a comparative analysis, J Med Virol, 78 (2006), pp. 683-692.

[12] J. Simpore, D. Ilboudo, A. Samandoulougou, P. Guardo, P. Castronovo, S. Musumeci HCV and HIV co-infection in pregnant women attending St. Camille Medical Centre in Ouagadougou (Burkina Faso)J Med Virol, 75 (2005), pp. 209212.

[13] J. Simpore, M. Granato, R. Santarelli, R. A. Nsme, M. Coluzzi, V. Pietra, et al. Prevalence of infection by HHV-8, $\mathrm{HIV}, \mathrm{HCV}$ and HBV among pregnant women in Burkina Faso J Clin Virol, 31 (2004), pp. 78-80.

[14] C. Laurent, A. Bourgeois, M. Mpoudi, C. Butel, E. MpoudiNgole, E. Delaporte HIV and hepatitis C virus coinfection, Cameroon Emerg Infect Dis, 13 (2007), pp. 514-516.

[15] D. N. Mbanya, D. Takam, P. M. Ndumbe Serological findings amongst first-time blood donors in Yaounde, Cameroon: is safe donation a reality or a myth? Transfus Med, 13 (2003), pp. 267-273.

[16] J. M. Pawlotsky, L. Belec, G. Gresenguet, L. Deforges, M. Bouvier, J. Duval, et al. High prevalence of hepatitis B, C, and E markers in young sexually active adults from the Central African Republic J Med Virol, 46 (1995), pp. 269-272.

[17] C. Laurent, D. Henzel, C. Mulanga-Kabeya, G. Maertens, B. Larouze, E. Delaporte Seroepidemiological survey of hepatitis $\mathrm{C}$ virus among commercial sex workers and pregnant women in Kinshasa, Democratic Republic of Congo Int J Epidemiol, 30 (2001), pp. 872-877.

[18] F. Rouet, M. L. Chaix, A. Inwoley, P. Msellati, I. Viho, P. Combe, et al. HBV and HCV prevalence and viraemia in HIV-positive and HIV-negative pregnant women in Abidjan, Cote d'Ivoire: the ANRS 1236 study J Med Virol, 74 (2004), pp. 34-40. 
[19] P. Combe, G. La Ruche, D. Bonard, T. Ouassa, H. Faye-Ketté, F. Sylla-Koko, et al. Hepatitis B and C infections, human immunodeficiency virus and other sexually transmitted infections among women of childbearing age in Cote d'Ivoire, West Africa.

[20] Obi SN, Onah HE, Ezugwu FO: Risk factors for hepatitis B infection during pregnancy in a Nigerian obstetric population. J ObstetGynecol 2006, 26: 770-772. Publisher Full Text.

[21] Kfutwah AK, Tejiokem MC, Njouom R: A low proportion of $\mathrm{HBeAg}$ among HBsAg-positive pregnant women with known HIV status could suggest low perinatal transmission of HBV in Cameroon. Virol J 2012, 9: 422X-9.
[22] Ndumbe PM, Skalsky J, Joller-Jemelka H: Seroprevalence of hepatitis and HIV infection among rural pregnant women in Cameroon. Apmis 1994, 102: 662-666. PubMed Abstract Publisher Full Text.

[23] Okoth F, Mbuthia J, Gatheru Z, Murila F, Kanyingi F, Mugo F, Esamai F, Alavi Z, Otieno J, Kiambati H: Seroprevalence of hepatitis B markers in pregnant women in Kenya. East Afr Med J 2009, 83: 485-493.

[24] Okada K, Kamiyama I, Inomata M, Imai M, Miyakawa Y, Mayumi M: e antigen and anti-e in the serum of asymptomatic carrier mothers as indicators of positive and negative transmission of hepatitis B virus to their infants. $N$ Engl J Med 1976, 294: 746-749. 